\title{
Geocronologia e proveniência de zircões detríticos em depósitos relacionados a glaciação extrema no Neoproterozoico do Mato Grosso do Sul, Brasil.
}

\section{Marcelo Da Roz de Campos*, Bernardo Tavares Freitas, Ticiano José Saraiva dos Santos.}

\section{Resumo}

O Neoproterozoico foi um período de grandes transformações ambientais no planeta, seu estudo fornece importantes informações a respeito da evolução da crosta terrestre, da evolução da vida e dos eventos climáticos extremos ocorridos na Terra. Neste trabalho é abordado o registro geológico de eventos climáticos extremos que precedem o surgimento da vida pluricelular na Terra por meio do estudo geocronológico e de proveniência de grãos de zircão detrítico no contexto da Faixa Paraguai. Enfase foi dada na obtenção de novos dados para a Formação Urucum (Grupo Jacadigo) e sua comparação com unidades correlacionáveis da Faixa Paraguai. A distribuição de idades encontrada para a Formação Urucum demonstra ser semelhante ao já publicado para outras unidades da Faixa Paraguai, sugerindo uma mesma conjuntura tectônica de aporte sedimentar. A grande diferença na distribuição de idades da Formação Guaicurus sugere uma reorganização regional das áreas fontes. Por fim, o zircão mais jovem encontrado nesse trabalho, com idade igual a $690 \pm 18$ Ma permitiu restringir o intervalo possível de idade para a Formação Urucum e o Grupo Jacadigo.

\section{Palavras-chave:}

Formação Urucum, Grupo Jacadigo, Faixa Paraguai.

\section{Introdução}

A Faixa Paraguai compreende uma espessa camada sedimentar depositada na porção sudoeste do Cráton Amazônico e do Bloco Rio Apa ${ }^{1}$. As unidades sedimentares da Faixa Paraguai guardam importantes informações acerca das mudanças climáticas e das transformações na crosta terrestre ocorridas no Neoproterozoico, assim como informações relevantes ao entendimento da evolução da vida na Terra.

Dessa forma, o presente trabalho teve como objetivo estudar essas unidades sedimentares através da geocronologia U-Pb em grãos de zircão detrítico com a finalidade de analisar a distribuição de idades entre as diferentes unidades e interpretar os padrões de produção e dispersão de sedimentos que deram origem a estas unidades.

\section{Resultados e Discussão}

No total, foram analisadas oito novas amostras para a Formação Urucum (Grupo Jacadigo), compondo um total de 1205 grãos analisados, dos quais 955 forneceram idades concordantes. o Grão mais jovem encontrado para a Formação Urucum possui uma idade igual a $690 \pm 18 \mathrm{Ma}$. Também foi feita uma releitura de dados geocronológicos presentes na literatura ${ }^{1,2,3,4}$ para as unidades correlacionáveis a Formação Urucum. Assim como a Formação Urucum, as outras unidades estudadas neste trabalho precedem amplas camadas carbonáticas ediacaranas, sendo que apenas a Formação Guaicurus não se encaixa neste contexto, localizando-se após essas camadas carbonáticas.

A Figura 1 mostra a distribuição de idades nas unidades geológicas analisadas. Os resultados mostram semelhanças nas distribuições de idades, com destaque para grãos com 1,7-1,9 $\mathrm{Ga}$, idades normalmente atribuídas ao embasamento da região ${ }^{3}$. Tais semelhanças sugerem que essas unidades compartilharam de um mesmo arranjo tectônico de aporte sedimentar. Já o diferente padrão de distribuição de idades para a Formação Guaicurus sugere a ocorrência de uma reorganização regional das áreas fontes.

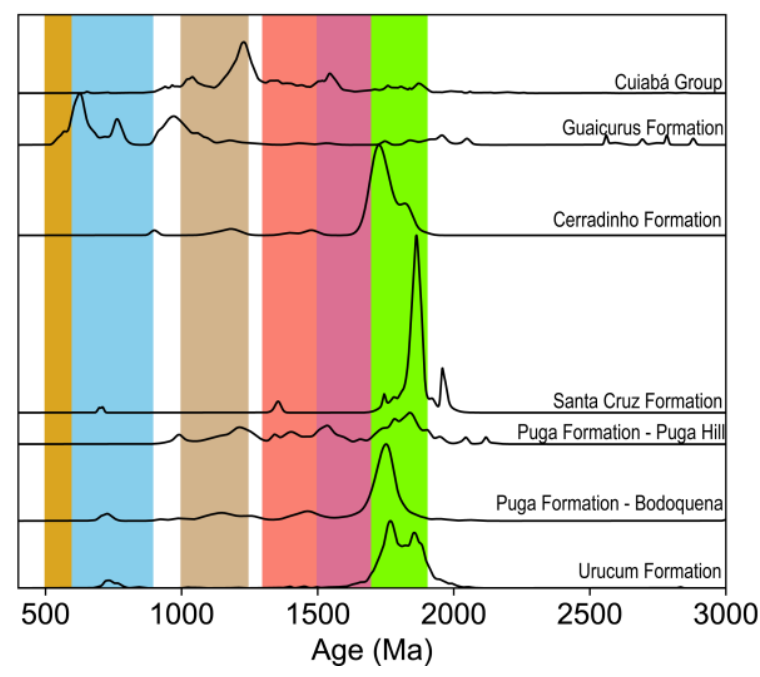

Figura 1. Curva de distribuição de Probabilidade para as unidades sedimentares da Faixa Paraguai.

\section{Conclusões}

Por um certo período de tempo as unidades sedimentares da Faixa Paraguai compartilharam de um mesmo arranjo tectônico de áreas fontes, o que é evidenciado pelas semelhanças entre as distribuições de idades. Porém, os dados da Formação Guaicurus mostram que em algum momento ocorreu uma reorganização regional das áreas fontes. Por fim, o grão mais jovem encontrado neste trabalho $(690 \pm 18 \mathrm{Ma})$ tornou possível restringir o intervalo de deposição para a Formação Urucum.

\section{Agradecimentos}

Ao PIBIC/CNPq pela bolsa IC e a FAPESP Processo 16/06114-6 pelo auxílio financeiro.

\footnotetext{
${ }^{1}$ Babinski M, Boggiani PC, Trindade RIF, et al. (2013). Gondwana Res. 23 , 988-997.

${ }^{2}$ Frei R, DØssing LN, Gaucher C, et al. (2017). Gondwana Res. 40, 1-20.

${ }^{3}$ McGee B, Babinski M, Trindade R, et al. (2018). Precambrian Res. 307, 1 33.

${ }^{4}$ Babinski M, McGee B, Tokashiki C, et al. (2018). J. South Am. Earth Sci. $85,6-42$.
} 